\title{
América Latina y la nueva legislación comercial de Estados Unidos
}

\section{INTRODUCGIÓN}

En este trabajo se examinan los aspectos fundamentales de la Ley de Comercio y Aranceles (ICA) de Estados Unidos y sus posibles consecuencias para los países de América Latina. Se sostiene, como tesis central, que mediante esta nueva ley, se refuerzan el carácter restrictivo de la legislación comercial norteamericana y se estimula el recurso a medidas unilaterales de protección, lo cual puede conducir a una mayor erosión del sistema multilateral de comercio y afectar de manera muy negativa los intereses comerciales de los países en desarrollo, incluidos los países latinoamericanos.

La LCA cubre una amplia gama de materias -de allí que durante el debate legislativo que le dio origen fuese denominada "ley omnibús"- y si bien fue presentada por la Administración Reagan como un triunfo de sus tesis librecambistas, un análisis detallado de la misma no permite llegar a tal conclusión. En realidad, la nueva ley está dirigida a promover los intereses comerciales de Estados Unidos sobre la base de criterios de reciprocidad y retaliación comercial y una aplicación más rigurosa de los procedimientos sobre salvaguardias y derechos compensatorios $y$ antidumping.

A diferencia de legislaciones anteriores, la LCA no promueve una mayor apertura del mercado norteamericano como estímulo para que otros países procedan de igual manera, sino que plantea mayores restricciones de acceso para las exportaciones de aquellos pafses que "obstaculicen" la expansión de las inversiones, bienes y servicios de Estados Unidos. De esta forma, la nueva legislación amplía el ámbito de la política comercial de Estados Unidos al incluir aspectos relacionados con el tratamiento a la inversión extranjera y al comercio internacional de servicios.

Además la ley modifica la naturaleza del esquema norteamericano de preferencias (SGP) de manera que el principio de no-reciprocidad, que le es consustancial prácticamente desaparece y el esquema es transformado en un instrumento de negociación para obtener 
Miguel Rodriguez Mendoza / Amética Latina y la nueva legislación...

concesiones de los países en desarrollo beneficiarios. Las normas relativas a salvaguardias y derechos compensatorios y antidumping, por su parte, son flexibilizadas con el propósito de facilitar a las empresas y otras entidades el recurso a la protección que estos procedimientos otorgan.

Todos estos cambios se discuten en detalle en las secciones que siguen. En la primera sección se analiza la orientación general de la ley y los mecanismos que ésta establece para el logro de los objetivos de política comercial de Estados Unidos; seguidamente, se examinan los cambios introducidos en el esquema norteamericano de preferencias; luego, se evalúan las modificaciones introducidas en materia de salvaguardias y aplicación de derechos compensatorios y antidumping; finalmente, se presentan algunas conclusiones y recomendaciones de polfticas que podrian servir a los países latinoamericanos para hacerle frente a las nuevas orientaciones y tendencias de la política comercial norteamericana.

\section{LOS OBJETIVOS DE POLÍTIGA GOMERGIAL DE EsTADOS UNIDOS}

La LCA establece los principales objetivos de política comercial de Estados Unidos para los próximos años. Estados Unidos se propone emprender negociaciones, a nivel multilateral y bilateral, con el propósito de lograr un marco legal internacional que facilite la "liberalización" del comercio de servicios y bienes de alta tecnología y la expansión de las inversiones norteamericanas en el extranjero. La LCA define las políticas y establece los procedimientos y los mecanismos necesarios para lograr estos objetivos, por lo que la nueva legislación comercial es, en realidad, un verdadero instrumento de política exterior.

Estados Unidos espera que los Ilamados "nuevos temas" (servicios, asuntos de inversión relacionados con el comercio y bienes de alta tecnología) sean el núcleo de una próxima ronda de negociaciones comerciales multilaterales (NCM). Es por ello que la LCA, anticipadamente, delimita los objetivos que los negociadores norteamericanos deben tratar de alcanzar. En lo que se refiere a Ios servicios, el objetivo fundamental es el establecimiento de un marco legal internacional, incluyendo mecanismos de solución de controversias, que permita la eliminación de las barreras u otras distorsiones que afectan al comercio de servicios. Con respecto a las inversiones extranjeras directas, la LCA postula la necesidad de lograr la aceptación y aplicación universal de criterios como el "trato nacional" y el "derecho de establecimiento". En relación a los bienes de alta tecnología, el propósito es el de lograr un régimen de libre comercio para el intercambio de estos productos, así como la modificación de las políticas nacionales y prácticas comercialels que pudieran distorsionar dicho régimen. 
En un sentido general, el principal objetivo negociador de la LGA parece ser el de lograr el máximo grado de libertad de operación para las empresas transnacionales de los Estados Unidos involucradas en la producción y el comercio de servicios. Estas empresas pueden operar en cualquier parte del mundo si se les otorga a) una presencia en el mercado extranjero ("derecho de establecimiento"), b) la capacidad de competir con las empresas locales ("rato nacional") y c) un flujo libre de datos desde la sede y hacia la sede (libertad para las corrientes transfronterizas de datos y para la ubicación de instalaciones de procesamiento de datos). Todos estos temas, como se ha señalado, están incluidos en la nueva legislación.

Para lograr estos objetivos, la LCA establece diversos procedimientos y mecanismos; negociaciones bilaterales en caso que la iniciativa para una nueva ronda NCM no prospere; negociaciones sectoriales en materia de servicios; utilización del SGP para lograr concesiones de los países en desarrollo beneficiarios; y mayor discrecionalidad del Ejecutivo para aplicar medidas de retaliación comercial.

En lo que respecta a las medidas de retaliación, la LCA modifica la Sección 301 de la Ley de Comercio de 1974. Esta Sección comprende diferentes instrumentos legales encaminados a lograr de los gobiemos extranjeros la eliminación o alteración de cualesquiera políticas o prácticas comerciales que los Estados Unidos consideren "desleales". Cuando la Oficina del Representante de Gomercio de los Estados Unidos (USTR) lleva adelante un caso comprendido en la Sección 30I, intenta primero negociar un arreglo con el gobierno extranjero. Si no ve la posibilidad de llegar a este arreglo, entonces el USTR puede usar sus poderes unilaterales para ejercer represalias mediante el aumento de los derechos de aduana o la aplicación de otras restricciones al acceso al mercado de los Estados Unidos.

La LCA amplía el alcance de la Sección 301 a los "nuevos temas" de servicios y asuntos de inversión relacionados con el comercio. Esto se hace por medio de nuevas definiciones, como la de "comer. cio", que ahora incluye los "nuevos temas" mencionados. La ley también define "injustificable" y "discriminatorio", con el fin de incorporar las tesis norteamericanas sobre el derecho de establecimiento y el tratamiento nacional para las inversiones extranjeras. Además, otra nueva definición, la de "irrazonable", coloca los intereses de los Estados Unidos por encima de la letra estricta de los acuerdos internacionales existentes en la medida en que se consideran "desleales" ciertas prácticas, políticas y otras medidas aun cuando éstas no sean contrarias a los compromisos internacionales asumidos por ese país. Los Estados Unidos pueden ejercer represalias en la forma de restricciones a las importaciones de bienes y/o servicios procedentes de los países que rehúsen aceptar sus nuevas exigencias en materia comercial. 
En buena medida, la LAC refleja un nuevo concepto de "reciprocidad" en las relaciones comerciales de Estados Unidos, que consis. tiría en la búsqueda, por parte de ese país, de oportunidades comerciales en terceros mercados que sean "sustancialmente equivalentes" a las que existen en el mercado norteamericano. La aplicación de represalias comerciales constituiría, en ese sentido, un importante instrumento de negociación. En lo que respecta a los "nuevos temas", que son los de indudable interés para Estados Unidos, la ley autoriza al Ejecutivo para que negocie el desmantelamiento de las políticas $u$ otras medidas que dificultan las inversiones $y$ las exportaciones de servicios norteamericanos, o para que logre su eliminación mediante la aplicación de medidas retaliatorias.

Ia LaA modifica también la operación de la Sección 301 con el fin de convertirla en un instrumento más flexible. EI USTR, a partir de ahora, puede iniciar investigaciones de oficio, demorar la iniciación de consultas con el fin de preparar un caso más adecuadamente, y aplicar represalias más severas en casos que envuelvan requisitos de exportación para las empresas. La LCA también ordena la presentación de un informe anual sobre barreras al comercio y las inversiones de los Estados Únidos. Este informe debe enfocar la atención de los Estados Unidos sobre prácticas específicas de países extranjeros. Las barreras al comercio de servicios están definidas en forma tal que incluyen restricciones sobre las corrientes transfronterizas de datos y la ubicación de instalaciones para el procesamiento de datos.

Aunque no ha sido frecuente la aplicación de medidas retaliatorias a América Latina por parte de Estados Unidos ${ }^{1}$, Ios cambios y nuevas orientaciones que introduce la LCA en la Sección 301 pueden revertir esta situación, con el agravante de que, en la medida en que los objetivos comerciales de Estados Unidos privilegian los asuntos relacionados con los servicios y las inversiones, lo que está en juego son las políticas nacionales de desarrollo de los países involucrados. Estados Unidos va a utilizar su poder retaliatorio para tratar de modificar las políticas internas y las prácticas comerciales que ese país considere "irrazonables", "discriminatorias", "injustificables" o simplemente "desleales", lo que incluiría, entre otros, los subsidios a la exportación y la producción las políticas de desarrollo industrial; las normas que rigen la aceptación y presencia de inversión extranjera y determinan su comportamiento ("export performance requirements"); las empresas del Estado, etc.

En consecuencia, Estados Unidos puede tratar de colocar sobre la mesa de negociaciones diversos aspectos de las estrategias de desa-

${ }^{1}$ Brasil $y$ Argentina son los únicos dos paises latinoamericanos que se han visto involucrados, recientemente, en casos de aplicación de la Sección 301. 
rrollo de América Latina y utilizar para ello las facultades retaliatorias ampliadas que le otorga la LCA. Este podría ser el caso, por ejemplo, de la reciente controversia entre México y Estados Unidos en relación con el decreto mexicano que regula la inversión extranjera en el sector farmacéutico; otro ejemplo es el del conflicto suscitado por el hecho de haber México rechazado la apertura de una nueva planta de la IBM. En el caso de Brasil, la nueva legislación sobre informática, mediante la cual ese país define una política para el desarrollo nacional del sector de la informática y el procesamiento de datos, ha sido objeto de fuertes críticas en Estados Unidos, por considerar que limita la presencia extranjera en un sector en que la industria norteamericana goza de amplias "ventajas comparativas". En ninguno de estos casos se han aplicado aún medidas retaliatorias, pero son áreas de conflictos potenciales que pueden tener serias consecuencias para los países involucrados. Este tipo de conflictos agregaría una nueva dimensión a las diferencias tradicionales entre América Latina y Estados Unidos en lo que respecta a las leyes, políticas y prácticas que regulan la inversión extranjera.

La LCA establece otros mecanismos para la acción en el contexto bilateral. Se dota al Ejecutivo de autorización para negociaciones bilaterales sobre la base de concesiones recíprocas, pero esta autorización es relativamente insignificante si se compara con el incremento de poderes para ejercer represalias. La LGA le otorga al Ejecutivo una autorización especial para la negociación de zonas de libre comercio recíprocas y bilaterales y de acuerdos sectoriales de liberalización del intercambio. Esta autorización fue concebida específicamente para ser empleada en negociaciones para el establecimiento de una zona de libre comercio entre los Estados Unidos e Israel, pero permite llevar adelante negociaciones semejantes con otros países a nivel sectorial. Es posible que los Estados Unidos y Canadá negocien un acuerdo de liberalización en materia de corrientes transfronterizas de datos.

\section{EL NUEVO SISTEMA GENERALIZADO DE PREFERENCIAS}

El SGP de los Estados Unidos, que garantiza acceso libre de derechos a numerosas exportaciones de países en desarrollo, debía expirar en enero de 1985. La LC̣A lo renovó por ocho y medio años, pero le fueron introducidos algunos cambios fundamentales. EI SGP renovado incluye varios elementos nuevos que podrían restringir el programa, particularmente para los países beneficiarios más avanzados. También altera completamente la naturaleza del sGP al introducir algunos requisitos de reciprocidad.

La LGA introduce la reciprocidad en el esquema del SGP mediante dos modificaciones destinadas a estimular a los países beneficiarios 
a que liberalicen su comercio con los Estados Unidos: un nivel más bajo de la "cláusula de la necesidad competitiva" (GNC) y.una autorización para suspender la aplicación de la CNG con respecto a algunos productos.

La LCA solicita al Ejecutivo que lleve a cabo revisiones periódicas de los productos elegibles para el sGP con el fin de identificar, sobre la base de países específicos, aquellos productos en que las naciones beneficiarias demuestren "un grado suficiente de capacidad para competir" (con respecto a otros países en desarrollo beneficiarios). Los productos que se consideren "competitivos" estarán entonces sometidos a una cNC que, en términos cuantitativos, es la mitad de la misma cNc aplicada a los demás productos: us\$25 millones o el 25 por ciento de las importaciones de Ios Estados Unidos de ese producto. EI efecto de esta CNC más baja será una "graduación" acelerada de estos productos. Una de las consideraciones que se tendrán en cuenta para determinar la capacidad de competencia de un producto será la disposición del país respectivo de liberalizar su comercio, particularmente en productos de interés para los Estados Unidos. En otras palabras, las consideraciones de orden político suplantarán los criterios económicos como determinantes principales de la capacidad para competir.

Adicionalmente, Ia LCA contempla una autorización presidencial para suspender la aplicación de la anc. La GNC puede ser suspendida a condición de que, entre otros criterios, el país en desarrollo beneficiario esté dispuesto a suministrar a los Estados Unidos un "acceso equitativo y razonable a su mercado y a sus recursos básicos y a proveer medios adecuados y efectivos, conforme a sus leyes, para que los extranjeros aseguren, ejerzan y hagan valer derechos exclusivos en propiedad intelectual, incluyendo patentes, marcas de fábrica y derechos de propiedad intelectual registrada (copyright)".

Esta situación establece un nuevo elemento de "elegibilidad negociable", que contribuirá, s'n duda, a la incertidumbre y condicionalidad del programa. Esto es particularmente cierto para los países beneficiarios de América Latina, debido a que la cNa excluye del sGe productos por un valor superior a los us $4,5 \mathrm{mil}$ millones (ver Cuadro I), Io que equivale a cerca del 40 por ciento de las exclusiones totales y es una cifra superior a la del valor del comercio latinoamericano que se beneficia del $\mathrm{SGP}^{2}$. En el caso de México, la cNc se aplica actualmente a productos de ese país por valor de us\$2,3 mil millones. La GNC restringe también el ingreso de productos brasileños y chilenos por un valor de cerca de us $\$ 450 \mathrm{mi}$ llones en cada caso. El ofrecimiento de recuperar los privilegios del sGe para estos productos será, sin duda, un importante instrumento de negociación para Estados Unidos.

Ver La Política Económica de los Estados Unidos y su Impacto en América Latina. Informe de la Secretaria Permanente del SELA, 17 de septiembre de 1984. 


\section{Cuadro 1}

EXGLUSIONES EN VIRTUD DE LA GLAUUSULA DE NEGESIDAD APLIGADAS A EXPORTAGIONES LATINOAMERICANAS REVISIONES DE 1981, 1982, 1983 Y 1984

(Miles de dólares) ${ }^{\mathrm{T}}$

\begin{tabular}{lrrrr}
\hline & 1981 & 1982 & 1983 & 1984 \\
\hline Argentina & 242.268 & 105.643 & 91.254 & 158.510 \\
Bolivia & 5.114 & 2.215 & - & - \\
Brasil & 537.742 & 255.795 & 426.267 & 602.009 \\
Colombia & 168.550 & 76.774 & 82.678 & 106.964 \\
Ghile & 228.357 & 352.754 & 453.039 & 198.357 \\
Costa Rica & 2.795 & 3.359 & 3.369 & - \\
Guatemala & 85.031 & - & - & - \\
Haití & 39.549 & 35.820 & 82.552 & 33.646 \\
Honduras & 3.794 & 10.489 & 3.099 & - \\
México & 1.224 .093 & 1.693 .914 & 2.278 .651 & 3.137 .414 \\
Panamá & 57.686 & - & - & - \\
Perú & 62.731 & 18.627 & 11.241 & 77.380 \\
República Dominicana & 340.279 & 112.516 & 176.952 & 201.648 \\
Venezuela & 45.443 & 61.008 & 202.565 & 42.338 \\
\multicolumn{1}{c}{ Total } & 3.037 & 2.698 .914 & 8.761 .667 & 4.558 .256 \\
& & & & \\
\hline
\end{tabular}

${ }^{1}$ Todos los valores se expresan en términos de flujos reales de comercio para el año de la revisión.

Fuente: Calculado a partir de informaciones suministradas por el Centro de Información sobre el SGP del UsrR.

En lo que se refiere a otros aspectos del SGP, la LGA no "gradúa" a ningún país específico, pero solicita al Ejecutivo que lleve a cabo una revisión de los países que se benefician del esquema y presente al Congreso un informe sobre la materia en enero de 1988. Entre los nuevos elementos que el Presidente debe "tener en cuenta" para la designación de un país como beneficiario del SGP, la ICA incorpora varios criterios con el proposito de determinar si dicho pais a) se abstiene de utilizar prácticas de exportación "no razonables"; b) suministra medios adecuados y efectivos conforme a sus leyes para que los extranjeros aseguren, ejerzan y hagan valer derechos exclusivos en propiedad intelectual, incluyendo patentes, marcas de fábrica y derechos de propiedad intelectual registrada; c) adopta medidas 
para reducir prácticas y políticas que afectan a Ia inversión -inclusive requerimientos de exportación para las empresas; y d) reduce - elimina obstáculos al comercio de servicios.

Todo parece indicar, por lo tanto, que la naturaleza global del SGP norteamericano ha sido cambiada a través de la introducción de requerimientos de reciprocidad y el programa no puede ser considerado, ahora, como un esquema autónomo por parte de los Estados Unidos, sino como un instrumento para obtener concesiones de parte de los países en desarrollo beneficiarios. En este sentido, el esquema se aleja completamente de los principios del SGP tal como fueron definidos en el marco de la unctad. Por otra parte, en el nuevo esquema no se tuvieron en cuenta las diversas proposiciones hechas por los países en desarrollo para el mejoramiento del sGP (como por ejemplo la extensión de la cobertura de productos y una mayor estabilidad), ni los compromisos asumidos por los Estados Unidos de llevar a cabo consultas previas con los países latinoamericanos antes de implantar cambios mayores en su esquema del $\mathrm{SGP}^{3}$.

\section{Acceso al mercado norteamericano}

La LCA contiene también un conjunto de disposiciones que directa o potencialmente afectan el acceso al mercado norteamericano, independientemente de las negociaciones que puedan tener lugar. Estas disposiciones a -i) la cláusula de salvaguardia; ii) la aplicación de derechos compensatorios y antidumping; y iii) diversas medidas aplicables a importaciones de productos específicos.

\section{Salvaguardias}

Ia legislación en materia de salvaguardias (Sección 201 de la Ley de Comercio de 1974), establece importantes recursos para limitar el acceso al mercado norteamericano de las importaciones que causan, o amenazan causar, "daño grave" a la industria local. En los últimos años la cláusula de salvaguardia ha sido usada en pocas ocasiones. Entre los casos más notables han estado los del cobre y el acero, en los cuales fueron involucrados varios países latinoamericanos.

Una de las razones que ha influido en la poca utilización de la cláusula de salvaguardia es que, según el Artículo XIX del GATT, ésta debe ser aplicada sobre una base no discriminatoria: un país que se considere afectado tiene el derecho, de acuerdo al GATT, de soli-citar compensación adecuada o retirar por su parte concesiones equivalentes. Otras de las razones es que los sectores industriales

${ }^{3}$ Ver Resolución REM/1-70 del Consejo Interamericano Económico y Social de la oEÁ (GIE), la cual se estableció en la Comisión Especial de Consulta y Negociación (CECON), vIr Reunión Extraordinaria del cIEs, Caracas, 3-6 de febrero 1970. 
afectados por las importaciones han preferido recurrir a la legislación sobre antidumping o derechos compensatorios, ya que ésta le otorga al Ejecutivo menos discrecionalidad de la que tiene en relación con la clásula de escape.

La LCA introduce algunos cambios básicos en la definición de "daño grave", con el propósito de facilitar a la 'Comisión de Comercio Internacional (ITC) la determinación de perjuicios a la industria local. Estos cambios Iimitan la discrecionalidad de la ITC en las investigaciones sobre salvaguardias y tienen su origen en diversos planteamientos formulados por la industria del calzado, a la cual la ITC le había negado previamente una solicitud para que limitara las importaciones de ese producto. La decisión de la ITa se basó en el hecho de que los fabricantes de calzado estaban entre los principales importadores del producto y sus ganancias globales eran adecuadas. Las modificaciones en la definición de "daño grave" que contempla la $L C A$ tienden a descartar este tipo de criterios en la determinación de los perjuicios actuales o potenciales a la industria local. Otro cambio que introduce la LCA se refiere a la posibilidad que tiene ahora el Congreso, por mayoría de dos tercios, de rechazar una decisión presidencial en materia de salvaguardias.

Como se puede observar en el Cuadro 2, Ios resultados de los procedimientos de salvaguardias que han tenido lugar en contra de exportaciones latinoamericanas han sido variados. En algunos casos la ITC no ha encontrado motivos para la imposición de medidas de salvaguardia. En otros, las recomendaciones de la ITC han sido rechazadas por el Presidente -el caso del cobre- o modificadas para otorgarle a la industria local un tipo de protección distinto al sugerido por la ITG, es el caso del acero, en qut la ITG recomendaba Ia imposición de cuotas y/o tarifas y el Presidente decidió negociar con los países involucrados acuerdos "voluntarios" de restricción de sus exportaciones. En otros casos, finalmente, las recomendaciones de la ITc han sido aceptadas (acero inoxidable y herramientas de aleación de acero). Por estas razones, es difícil predecir la medida en que los países latinoamericanos serán afectados por las modificaciones introducidas por la LCA en materia de salvaguardias. Será necesario esperar hasta que se pongan en práctica los nuevos criterios antes de hacer una evaluación definitiva.

\section{Derechos compensatorios y antidumping}

La legislación sobre derechos compensatorios y antidumping también es modificada sustancialmente por la LCA. Las modificaciones introducidas son resultados de la opinión prevaleciente en el Congreso norteamericano en el sentido de que: 1) los procedimientos actuales son demasiado complejos, costosos y lentos para las empresas norteamericanas, particularmente las pequeñas empresas; y 2) las 
Miguel Rodriguex Mendoza / América Latina y la nueva legislación...

Cuadro 2

APLIGAGIÓN DE LA CLÁUSULA DE SALVAGUARDIA A PRODUCTOS ACTUAL O POTENGIALMENTE EXPORTADOS POR PAISES

LATINOANERICANOS

1981-1984

\begin{tabular}{|c|c|c|c|}
\hline Productos & Veredicto ITC & \multicolumn{2}{|c|}{$\begin{array}{l}\text { Acción del } \\
\text { Presidente }\end{array}$} \\
\hline $\begin{array}{l}\text { Cañas de pescar y piezas } \\
\text { de éstas. }\end{array}$ & $\begin{array}{l}\text { Negativo. } \\
\qquad(25-11-81)\end{array}$ & & - \\
\hline $\begin{array}{l}\text { Válvulas para llantas, } \\
\text { sin tripa. }\end{array}$ & $\begin{array}{l}\text { Negativo. } \\
\text { (20-9-82). }\end{array}$ & & - \\
\hline $\begin{array}{l}\text { Acero inoxidable y acero } \\
\text { de aleación para } \\
\text { herramientas. }\end{array}$ & $\begin{array}{l}\text { Afirmativo: } \\
\text { recomendó aranceles, } \\
\text { cuotas y AvRs. } \\
(6-5-83) \text {. }\end{array}$ & Otorgó alivio. & \\
\hline $\begin{array}{l}\text { Utensilios de mesa de } \\
\text { acero inoxidable. }\end{array}$ & $\begin{array}{l}\text { Negativo. } \\
\text { (13-6-84). }\end{array}$ & & - \\
\hline Calzado no de goma. & $\begin{array}{l}\text { Negativo. } \\
\quad(9-7-84)\end{array}$ & & - \\
\hline $\begin{array}{l}\text { Carbón y ciertos } \\
\text { productos de acero } \\
\text { aleado. }\end{array}$ & $\begin{array}{l}\text { Afirmativo: } \\
\text { recomendo aranceles por } \\
5 \text { años y un programa de } \\
\text { cuotas. }(24-7-84) \text {. }\end{array}$ & $\begin{array}{l}\text { Otorgó alivio } \\
(20-9-84)\end{array}$ & limitado \\
\hline Cobre no elaborado. & $\begin{array}{l}\text { Afirmativo: } \\
\text { recomendó aranceles más } \\
\text { elevados o cuotas. } \\
(16-7-84) \text {. }\end{array}$ & $\begin{array}{l}\text { Negó alivio. } \\
(5-9-84)\end{array}$ & \\
\hline Gierto atún enlatado. & $\begin{array}{l}\text { Negativo. } \\
\quad(29-8-84) .\end{array}$ & - & \\
\hline
\end{tabular}

FUENTES Informaciones anuales de la Comisión de Comercio Internacional (CCI) de Estados Unidos.

leyes de los Estados Unidos son insuficientes para hacer frente a las prácticas comerciales "desleales" de otros países.

Si bien la mayoría de las enmiendas introducidas en materia de derechos compensatorios y antidumping representan una compilación de prácticas ya existentes así como una aclaración de procedimientos, el propósito de estas enmiendas es hacer más simple la iniciación de investigaciones por parte de los demandantes y facilitar 
la determinación de daños. Esto se logra, entre otros, mediante la extensión de la cobertura de las investigaciones sobre derechos compensatorios y antidumping a productos que aún no han sido importados ("likely sales"); la posibilidad de iniciar investigaciones de oficio por parte del Departamento de Comercio en casos de "dumping persistente" que involucren a más de un país; y la opción de conducir simultáneamente investigaciones sobre derechos compensatorios y antidumping en relación con el mismo producto proveniente de los mismos países, facilitando de esta manera la obtención de protección del demandante bajo ambos procedimientos.

Entre las principales modificaciones introducidas por Ia LCA a la legislación sobre derechos compensatorios y antidumping podría señalarse la adición de los "upstream subsidies" a la lista de subsidios prohibidos que pueden dar lugar a derechos compensatorios. Este concepto no está considerado en el Código de Subsidios del GATr ni en la Ley de Aranceles de Estados Unidos de 1930, pero ha evolucionado como una práctica sui generis del Departamento de Comercio. El Título vi de la ICA incluye por primera vez este concepto. Se consideran "upstream subsidies" aquellos que son otorgados a algunos de los principales componentes de un producto y no al producto mismo.

La LGa también señala los criterios adicionales que la ITG debe tomar en cuenta al establecer si una determinada práctica comercial causa o amenaza causar "daños materiales" a la industria norteamericana. El más importante de estos criterios se refiere a la "acumulación" de importaciones provenientes de diferentes proveedores para efectos de las investigaciones sobre derechos compensatorios y antidumping. Al "acumular" las importaciones de varios países aumentan las posibilidades de que la ITc determine que ésestas causan "daños materiales" a la industria local. Los principales países afectados serán los pequeños exportadores que, en ausencia de estos criterios, difícilmente podrían ser acusados de perjudicar a la industria norteamericana. Debe señalarse, además, que estos criterios de "acumulación", que tampoco están contemplados en el Código de Subsidios del GaTT, pueden afectar el balance de derechos y obligaciones entre Estados Unidos y los paises que han suscrito el mencionado Código.

La legislación norteamericana sobre derechos compensatorios y antidumping tiene una gran importancia para América Latina y Estados Unidos. Como se puede observar en los Cuadros 3 y 4 a diversos países de la región se les han aplicado con frecuencia estos procedimientos. En su conjunto, América Latina ha sido objeto de un tercio de todos los derechos antidumping aplicados a países en desarrollo en los últimos cuatro años y de más de la mitad de los procedimientos actualmente en curso. La aplicación de derechos compensatorios a países latinoamericanos en ese mismo período ha 
Miguel Rodriguez Mendoza / América Latina y la nueva legislación...

sido aún más frecuente y representa la casi totalidad de las medidas de este tipo aplicadas a países en desarrollo. México y Brasil han sido los parses de la región más afectados.

Las modificaciones que introduce la LCA en esta materia, por lo tanto, son altamente preocupantes para América Latina. Yá el Departamento de Comercio ha iniciado investigaciones para determinar si existen "upstream subsidies" en ciertos útiles de escritorio que son exportados por México y en algunos productos agrícolas brasileños. En lo que se refiere a la "acumulación" de importaciones, Venezuela es objeto de una demanda sobre derechos compensatorios y antidumping por parte de la us Steel, en la que se algea que el efecto de las importaciones venezolanas al mercado norteamericano -relativamente pequeñas y por lo tanto difícilmente causantes de perjuicios a la industria local- debe ser considerado conjuntamente con el de las importaciones provenientes de otros seis países proveedores. Los resultados de las investigaciones mencionadas aún no se conocen, pero es evidente que su sola existencia es una causa adicional de inestabilidad en las relaciones comerciales de América Latina con Estados Unidos.

\section{Cuadro 3}

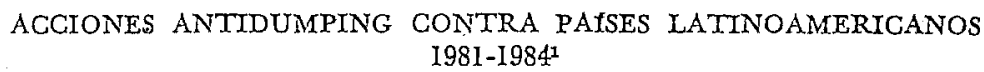

Decisiones definitivas

\begin{tabular}{llc}
\hline Pafs Nerminada & Negativa & $\begin{array}{c}\text { Afirmativa } \\
\text { (AD aplicado) }\end{array}$ \\
\hline
\end{tabular}

América Latina:

$\begin{array}{lcccc}\text { Brasil } & - & 2 & 3 & 3 \\ \text { Chile } & - & - & 2 & - \\ \text { México } & - & - & 1 & 1 \\ \text { Trinidad \& Tobago } & - & - & 1 & - \\ \text { Colombia } & \text { I } & 1 & - & - \\ \text { Venezuela } & 1 & - & - & 3 \\ \text { Argentina } & - & - & - & 7 \\ \quad \text { Subtotal: } & 2 & 3 & 7 & 6 \\ \text { Other PMDs: } & 7 & 4 & 14 & 13(26 \%) \\ \quad \text { Total: } 50 & 9(18 \%) & 7(14 \%) & 21(42 \%) & \end{array}$

IEl cuadro no incluye peticiones introducidas ante el Departamento de comercio que no pasaron de la fase inicial de investigación.

${ }^{2} \mathrm{~A}$ partir del 19 de noviembre de 1984.

Fuente: Calculado en base a información suministrada por el Grupo de Computación del ustr. 


\section{Cuadro 4}

ACCIONES DE DEREGHOS COMPENSATORIOS GONTRA

PAISES LATINOAMERICANOS: 1981-1984

Decisiones definitivas

\begin{tabular}{|c|c|c|c|c|}
\hline País & $\begin{array}{l}\text { Terminada } \\
\text { o suspendida }\end{array}$ & Negativa & $\begin{array}{c}\text { Afirmativa } \\
\text { (cVD aplicado) }\end{array}$ & Pendiente $^{2}$ \\
\hline
\end{tabular}

AMERICA LATINA:

$\begin{array}{lcccc}\text { México } & 4 & 1^{2} & 12 & 5 \\ \text { Brasil } & 8 & 4 & 4 & 5 \\ \text { Argentina } & 1 & - & 2 & 2 \\ \text { Perú } & 1 & - & 2 & 1 \\ \text { Uruguay } & - & - & 1 & - \\ \text { Colombia } & 1 & - & - & - \\ \text { Panamá } & 1 & - & - & - \\ \text { Costa Rica } & - & - & - & 1 \\ \quad \text { Subtotal: } & 16 & 5 & 23 & 14 \\ \text { Other PVDs: } & 8 & - & 4 & 12 \\ \quad \text { Total: } & 25(81 \%) & 4(5 \%) & 27(33 \%) & 25(31 \%)\end{array}$

${ }^{1} \mathrm{El}$ cuadro no incluye peticiones introlucidas ante el Departamento de Comercio que no pasaron a la fase inicial de investigación.

${ }^{2} \mathrm{~A}$ partir del $1^{\text {o }}$ de noviembre de 1984.

${ }^{3}$ El veredicto negativo fue tomado por el Departamento de Comercio; la Comisión de Comercio Internacional no aplica la prueba de daño a México.

FUENTE: Calculado en base a información suministrada por el Grupo de Computación del USTR.

\section{Otras disposiciones}

La LCA también se refiere al mercado norteamericano del acero y al nivel de importaciones de productos de acero que será permitido en Ios próximos años. La LCA especifica que es el "parecer del Congreso" que el porcentaje del mercado del acero de los Estados Unidos cubierto por importaciones debe estar en el rango del 17 al 20 por ciento y estar "sometido a las modificaciones que sean necesarias en virtud de cambios en las condiciones del mercado y en la composición de la industria deI acero". El margen porcentual señalado representa una transacción entre el plan para reducir las importaciones de acero diseñado por el Ejecutivo norteamericano y el plan 
del Partido Demócrata. El Presidente queda autorizado para "llevar a cabo las acciones que puedan ser necesarias o apropiadas para poner en ejecución las limitaciones cuantitativas, restricciones y otros términos a los cuales se hace refreencia en los arreglos bilaterales", esto es, en los acuerdos sobre restricciones "voluntarias" a las exportaciones de acero que Estados Unidos ha negociado con los principales proveedores. Esta autorización durará cinco años y solamente podrá prorrogarse sobre la base de lal cooperación por parte de los productores estadounidenses de acero en relación con diversas medidas de ajuste (modernización de plantas, entrenamiento, etc.) contempladas en la ley. Aunque este "parecer del Congreso" no es obligatorio para el gobierno, la Ley agrega que "si la política nacional para la industria del acero no produce resultados satisfactorios, el Congreso considerará la posibilidad de adoptar (ulteriores) acciones legislativas...".

Como resultado de las negociaciones sobre restricciones "voluntarias" a las exportaciones de acero, a México y Brasil se les ha asignado una participación del mercado de 0.36 por cient oy 0.80 por ciento (sin incluir productos de acero semiterminados), respectivamente. El ustR intentó negociar un acuerdo de restricciones "voluntarias" con Argentina, pero no se llegó a un acuerdo antes de que expirara el plazo establecido. No se llevaron a cabo negociaciones al respecto con Venezuela, ni con Trinidad y Tobago, pero la U.s. Steel, como ya se ha mencionado, presentó recientemente una serie de peticiones de derechos antidumping contra las exportaciones venezolanas de láminas, hojas laminadas en frío y en caliente y láminas galvanizadas.

La LCA contiene asimismo una enmienda significativa en cuanto a los requerimientos de marcas de origen para diferentes clases de tubos de acero. Dichos productos deben ser "marcados con el nombre inglés del país de origen por medio de estampado (die stamping), letras fundidas en molde (cast-mold), aguafuerte (etching) o grabado". Los productores e importadores de acero extranjero se han quejado de que esta medida constituye una barrera no arancelaria, puesto que marcas de esta naturaleza podrían dañar la integridad del acero. La Comunidad Europea ha solicitado formalmente consultas con los Estados Unidos. conforme al Artículo xxrr del GATT, con respecto a estas medidas y ha reservado su derecho a jercer las acciones correspondientes en el contexto del Gódigo sobre Barreras Técnicas al Comercio.

La LCA incluye otro "parecer del Congreso", en que se solicita al Presidente que negogcie acuerdos sobre restricciones "voluntarias" con los productores extranjeros de cobre para logxar la reducción de su producrión de ese producto. Si el Presidente tomara en cuenta este "parecer del Congreso", podrían tener lugar negociaciones muy difíciles con Chile y otros exportadores de cobre. No es probable, 
sin embargo, que esto suceda. La disposición no es obligatoria para el Presidente y no le exige iniciar o concluir negociaciones para lograr estos acuerdos. Su única obligación es presentar, en el plazo de un año, un informe en el que explique el resultado de las negociaciones o las razones por las cuales él consideró inapropiado o innecesario emprender tales negociaciones.

\section{Conclusiones}

La LGA constituye un instrumento de negociación de amplio alcan. ce para la expansión de los intereses comerciales y las inversiones de Estados Unidos. Sus disposiciones tienden a aumentar la protección de las industrias norteamericanas frente a la competencia externa y establecen los mecanismos que podrá utilizar Estados Unidos para promover la liberalización del mercado internacional de servicios, alta tecnologfa e inversiones, en beneficio de los sectores más dinámicos de la economfa norteamericana.

Desde la perspectiva de América Latina, la LGA puede tener como efecto inmediato no sólo dificultar el acceso de sus exportaciones al mercado de Estados Unidos, sino también condicionar tal acceso al grado de compatibilización entre las políticas nacionales de desarrollo y los intereses de Estados Unidos que estén dispuestos a aceptar los países de la región.

Los objetivos comerciales de Estados Unidos constituyen, un desafío directo para muchas de las políticas latinoamericanas en comercio e inversiones. La estrategia que adoptará Estados Unidos para llevar a cabo estos objetivos, específicamente en lo que se refiere a los "nuevos temas", recae dentro de las facultades que le otorga la LCA al Ejecutivo. Desde 1982 Estados Unidos viene propugnando la vía multilateral, en el ámbito del GATT, sin embargo, ha anunciado que, de no lograrse un consenso para la negociación de una normativa multilateral procederá a entablar negociaciones bilaterales.

La LGA se adopta en una coyuntura particularmente crítica para América Latina. En una perspectiva de corto y mediano plazo, el incremento de los ingresos por exportaciones es indispensable para el financiamiento del desarrollo. En el largo plazo, la autonomía en los sectores de servicios y tecnología, así como el control de la orientación de los flujos de inversiones pueden estimarse críticos para la orientación del desarrollo a niveles nacional y regional. En ambas esferas, las implicaciones de la LGA pueden ser determinantes.

Los objetivos de negociación en el ámbito comercial que plantea la LCA deberían ser analizados ampliamente por los países latinoamericanos a fin de determinar las posibles consecuencias para sus economfas y, sobre esa base, adoptar lineamientos de política económica internacional. A este respecto, se deberfan tener en cuenta 
a) la evolución de las discusiones internacionales sobre servicios y la conveniencia de fortalecer la acción colectiva en estas discusiones; y b) la necesidad de estudiar sus economfas con el fin de evaluar la contribución de los servicios a su propio desarrollo económico y, sobre esa base, definir las políticas a seguir a nivel internacional. Esto estaría en consonancia con las decisiones adoptadas por los paises latinoamericanos en el marco del SELA en esta materia. Una preocupación fundamental de los países latinoamericanos ha sido la de identificar modalidades de cooperación regional en el campo de los servicios. En efecto, un incremento del comercio de servicios sería más factible como consecuencia de un enfoque cooperativo y orientado hacia el desarrollo. Este enfoque permitiría a los países en desarrollo promover ciertas industrias propias de servicios $y$, al mismo tiempo, obtener otros servicios de fuentes extranjeras, en lugar de acudir a un escenario de regateos recíprocos con Estados Unidos bajo la amenaza de represalias contra sus exportaciones de bienes. Este último procedimient opodría conducir a Ios países, incluso, a aumentar sus reglamentaciones del sector de los servicios con el fin de mejorar su posición negociadora.

El impacto del nuevo SGP de los Estados Unidos debe también analizarse en este contexto. Los países latinoamericanos debieran tener en cuenta la importancia relativa del esquema vis à vis las concesiones posibles que Estados Unidos podría estar tratando de obtener en las áreas de comercio, servicios, inversiones, etc. Si bien los beneficios del s.GP varían de país a pafs, en general los requerimientos norteamericanos parecen superar estos beneficios. Esta modificación radical del SGP norteamericano debería provocar no sólo una reacción individual por parte de los países latinoamericanos; también debería examinarse la conveniencia de una respuesta general por parte de América Latina y de los países en desarrollo en su conjunto en los foros internacionales adecuados (i.e., UNCTAD, GATT).

En general la LGA confirma la tendencia, identificada en foros multilaterales tales como la UNCTAD y el GATT, hacia el "comercio administrado". El comercio está siendo administrado de tal manera que reduce a los nuevos participantes -tales como los paises latinoamericanos exportadores de acero- a una proporción insignificante del mercado. De este modo, el acero se ha reunido con los textiles y otros posibles candidatos han sido ya identificados para acciones de esta naturaleza: el cobre, por ejemplo.

De la misma manera, las modificaciones introducidas en la legislación sobre salvaguardias y derechos compensatorios y antidumping, así como las otras disposiciones de la LCA relativas al cobre y el acero, tienen como propósito el facilitar el acceso a medidas proteccionistas por parte de la industria local o a satisfacer intereses de sectores particulares. Estas modificaciones pueden traducirse no sólo en una mayor imposición de medidas restrictivas, sino también en 
una multiplicación de demandas en contra de importaciones provenientes de países en desarrollo, todo lo cual aumentará la inestabilidad e incertidumbre en relación a las condiciones de acceso al mercado norteamericano.

Las crecientes posibilidades de un acceso restringido al mercado de los Estados Unidos para América Latina invita a esfuerzos intensos para defender los intereses de los exportadores de la región. Estos esfuerzos podrían comprender un asesoramiento jurídico y de consultores y una representación de más amplio alcance. Dados los gastos involucrados en una estrategia semejante, podrían explorarse modalidades para compartir gastos entre países latinoamericanos. Esta acción podría incluir un sistema considerablemente mejorado de inteligencia comercial y de transmisión de información relativa a los desarrollos legales estadounidenses con posibles consecuencias para el comercio latinoamericano. Además, se deberían examinar las acciones colectivas que podrían utilizarse para influir, en favor de Ios países latinoamericanos, las decisiones del 'Congreso y el Ejecutivo norteamericano. Finalmente, los países latinoamericanos podrían establecer mecanismos informales para el intercambio recíproco de información en relación con los conflictos comerciales en que se vean involucrados con Estados Unidos.

Al nivel multilateral -esto es, en el GATr y en la UNCTAD- los países latinoamericanos podrían poner énfasis en el vínculo entre la tendencia continuada de la legislación comercial estadounidense a disposiciones más proteccionistas y discriminatorias, la cual, si llega a perpetuarse, podría debilitar la credibilidad de las concesiones comerciales de los Estados Unidos y deteriorar aún más el sistema de comercio multilateral. Un enfoque de esta naturaleza sería particularmente importante como respuesta a las presiones que los Estados Unidos ejercen para una nueva ronda de negociaciones comerciales multilaterales. El requisito previo de una aquiescencia latinoamericana a negociaciones de esa naturaleza, podría ser la adopción de medidas específicas por parte de los Estados Unidos que demostraran la voluntad política de dicho país de dar marcha atrás en su tendencia hacia el proteccionismo. Al mismo tiempo, los países latinoamericanos que son partes contratantes del GATT deberian vigilar de cerca y defender cuidadosamente los derechos que les confiere el Acuerdo General cuando sean afectados por medidas aplicadas por los Estados Unidos conforme a la Ley de Aranceles y Comercio de 1984 y apoyar las acciones a este respecto que pudieran ejercer países de fuera de la región. 